\title{
Por quê confiamos nas instituições? O caso boliviano
}

\author{
Vivian Schwarz-Blum \\ Vanderbilt University
}

\begin{abstract}
Resumo
A Bolívia passou por um grande processo de reforma institucional desde seu retorno à democracia, em 1982, reconhecido internacionalmente como um dos mais profundos da América Latina. Apesar de todos os esforços do Estado boliviano para aperfeiçoar e modernizar suas instituições, e apesar das reformas bem sucedidas em setores fundamentais do governo, a Bolívia tem um dos níveis mais baixos de confiança nas instituições dos países latino-americanos e os dados mostram indícios de que a confiança nas instituições políticas tende a diminuir com o tempo. Ao mesmo tempo, a Bolívia é o país mais pobre da América do Sul; tem os graus mais altos de corrupção na administração pública e, nos últimos anos, um ambiente político cada vez mais instável. Há indícios de que os efeitos de uma polarização regional de interesses, as percepções negativas da situação econômica e da corrupção e níveis baixos de conhecimento político da população boliviana sejam preditores confiáveis dos baixos níveis de confiança institucional que consistentemente encobrem a melhoria do desempenho institucional dos governos bolivianos.
\end{abstract}

Palavras-chave: confiança institucional, interesses regionais, situação econômica, Bolivia

\begin{abstract}
Bolivia has undergone a deep process of institutional reform since its return to democracy in 1982 that is recognized internationally as one of the deepest in the Latin American region. Despite all the efforts of the Bolivian state to improve and modernize its institutions, Bolivia has one of the lowest levels of institutional trust among Latin American countries and data show evidence that trust in political institutions tends to decrease over time. At the same time, Bolivia is the poorest country in South America; it has high levels of corruption in the public administration and in the last years an increasingly unstable political environment. Evidence indicates that the effects of a regional polarization of interests, the negative perceptions of the economic situation and of corruption and low levels of political knowledge among the Bolivian population are reliable predictors of low levels of institutional trust that consistently overshadow the accomplishments of Bolivian governments in improving their institutional performances.
\end{abstract}

Key words: institutional trust, regional interests, economic situation, Bolivia 
Desde o retorno à democracia, em 1982, a Bolívia passou por um profundo processo de reforma institucional intensificado na última década. Na região latinoamericana, a Bolívia é provavelmente o país que reformou mais suas instituições políticas e com mais profundidade do qualquer outro país (SELIGSON et al., 2004b).

Durante esse período, o Estado boliviano investiu recursos humanos e econômicos na modernização de sua máquina burocrática em setores fundamentais e suas instituições foram reformadas, aperfeiçoadas, reorientadas, bem como novas instituições foram criadas a fim de tornar mais eficiente o desempenho do aparato do Estado. ${ }^{1}$ Leis como a de Descentralização e Participação Popular não somente mudaram a configuração política do país, como também foram instrumentos úteis para a expansão do espaço público e para a integração ao processo político de atores tradicionalmente relegados.

Por meio de suas múltiplas reformas institucionais, o Estado melhorou consideravelmente o reconhecimento e a defesa dos direitos humanos e civis; reconheceu novos atores políticos e os integrou ao sistema político; descentralizou bastante a administração pública e trabalhou muito para aperfeiçoar os processos políticos participatórios em todo o território nacional (SELIGSON, 2003; SELIGSON et al., 2004a; SELIGSON et al., 2004b). Levando-se todos esses fatores em conta, o processo de reforma institucional na Bolívia pode ser considerado bem sucedido do ponto de vista institucional, apesar dos problemas políticos que persistem no país até hoje.

Ao mesmo tempo, dados do LAPOP 2 apresenta indícios que sugerem que a Bolívia é atualmente um dos países da América Latina com níveis mais baixos de confiança nas instituições políticas e de apoio ao sistema.

Os problemas não acabam aí. O país vive em regime democrático nos últimos 23 anos, mas a democracia se desenvolveu num contexto contraditório de pobreza, debilidade institucional, crises constantes e conflitos recorrentes entre as elites governantes e os setores econômicos desfavorecidos e, ao mesmo tempo, com expansão do espaço público, descentralização, processos participatórios e reformas institucionais.

\footnotetext{
${ }^{1}$ Em nível nacional, há novas instituições como o Defensor do Povo, o Tribunal Constitucional, um órgão de Defesa de Crianças e Adolescentes, e a Brigada de Defesa das Mulheres e da Família. As municipalidades e os comitês de vigilância municipal também podem ser considerados instituições relativamente novas no sistema político, pois existem há apenas uma década.

2 O Projeto de Opinião Pública Latino-Americana (LAPOP) é dirigido pelo professor Mitchell A. Seligson na Vanderbilt University. O LAPOP realiza estudos de opinião pública sobre atitudes democráticas em onze países das Américas Central e do Sul e vem estudando as características da democracia boliviana desde 1998.
} 
A Bolívia é o país mais pobre da América do Sul e obteve apenas 2,2 pontos no Índice de Percepção da Corrupção ${ }^{3}$ calculado pela Transparência Internacional para 2004. O Barômetro Global da Corrupção da Transparência Internacional apresenta os níveis de corrupção percebida em diferentes instituições em países de todo o mundo, e os índices de corrupção percebida nas instituições políticas da Bolívia estão entre os mais altos, com exceção das avaliações feitas de ONGs e organismos religiosos. (ver Anexo)

E para completar o cenário, a instabilidade política aumentou nos últimos três anos, nos quais dois mandatos presidenciais foram interrompidos antes de seu final e dois presidentes foram obrigados a renunciar devido à insatisfação popular com o desempenho do governo. Os protestos públicos e choques entre o governo e grupos civis foram comuns e a alegada inviabilidade do Estado boliviano tornou-se uma realidade no momento da renúncia do presidente Carlos Mesa, que teve de sair apesar de gozar de alto grau de apoio popular (SELIGSON, MORENO-MORALES et al., 2004). Foi difícil até mesmo encontrar com um substituto constitucional de consenso para o presidente Mesa.

É paradoxal que os níveis de confiança institucional dos bolivianos sejam tão baixos e que pareçam estar em constante queda, apesar dos esforços que o Estado boliviano tem feito para transformar a estrutura política e o desempenho do sistema político. Parece que os problemas de instabilidade política, economia débil e corrupção impedem que o público boliviano veja os sucessos e as melhorias realizadas pelo Estado. Esse paradoxo é a idéia diretriz deste artigo.

\section{A importância da confiança política}

A confiança política pode ser definida mais como uma atitude do que como um comportamento, pois é o resultado de uma avaliação passiva do desempenho de objetos políticos quanto à expectativa de seu desempenho, a qual não produz necessariamente uma ação como conseqüência (EASTON, 1965; EASTON, 1975). A confiança desempenha um papel essencial na percepção da legitimidade dos atos de um governo ou de um regime e, portanto, do nível de apoio ao regime e ao governo que um indivíduo pode expressar. É apoio, embora aquele que provavelmente se traduzirá em uma ação quando o nível de confiança proporcionar parte da justificativa dessa ação.

\footnotetext{
${ }^{3}$ O escore para a Bolívia em 2005 é de 2.5 pontos numa escala de 0 a 10. Para mais detalhes sobre os escores da Bolívia, consultar http://legacy.transparency.org/cpi/2005/cpi2005.sources.en.html.
} 
Hetherington define confiança política como "o grau em que as pessoas percebem que o governo está produzindo resultados consistentes com as expectativas delas" (HETHERINGTON, 2005). Essa definição é útil porque introduz a idéia de confiança como resultado de uma comparação entre percepções das pessoas e suas expectativas, combinando assim uma dimensão empírica com uma normativa.

Baseados na definição de confiança de Hetherington, para os propósitos de análise deste trabalho, definiremos confiança política como o grau em que as pessoas percebem que o processo político está estruturado de um modo consistente com suas expectativas. Essa definição exige uma medida da confiança política relacionada às instituições, pois as instituições são elementos duradouros de um regime e podem ser avaliadas independentemente do grupo de pessoas que está no governo. Com esse propósito, este trabalho considerará que as instituições políticas são "as estruturas formais de governo e as regras que afetam sua operação", como Barry Ames as define.

Quanto ao motivo da importância atribuída à confiança política, Mishler e Rose discutem extensamente sua importância para o sistema político no contexto das sociedades pós-comunistas e sustentam que "a confiança popular nas instituições políticas e sociais é vital para a consolidação da democracia" e, além disso, que "a confiança é importante [...] porque serve como "criadora de poder coletivo', permitindo que o governo tome decisões e comprometa recursos sem ter de apelar para a coerção ou obter a aprovação específica dos cidadãos para cada decisão" (MISHLER e ROSE, 1997). Assim, a confiança política aumenta a eficácia e a eficiência do governo.

A confiança também é importante nos regimes democráticos porque é um elemento-chave da relação de representação entre as autoridades eleitas e os cidadãos (MISHLER e ROSE, 1997). Se os cidadãos não confiarem em seus representantes eleitos, as decisões tomadas não terão legitimidade e, portanto, dificilmente serão implementadas. Em seu modelo para medir a legitimidade política, Weatherford considera a confiança política um dos elementos essenciais da legitimidade (WEATHERFORD, 1992). ${ }^{4}$

A importância da confiança é evidente também na sociedade civil, pois propicia a base para a criação de instituições civis tais como sindicatos, associações, comitês e até partidos políticos, que são complementares às instituições políticas e podem aumentar sua eficácia (MISHLER e ROSE, 1997). A confiança estimula a participação voluntária na política e, mediante a criação de instituições civis, oferece aos cidadãos um canal alternativo de participação na vida política.

\footnotetext{
${ }^{4}$ Para uma discussão complementar da legitimidade política, ver LIPSET, 1961.
} 
As evidências de como a confiança política pode influenciar as escolhas de políticas públicas das autoridades governamentais e até as linhas ideológicas gerais ao longo do tempo são amplamente explicadas no estudo de Hetherington sobre a sua importância na política americana (HETHERINGTON, 2005) e no estudo de Miller sobre a confiança no governo na década de 1970 (MILLER, 1974), entre muitos outros.

Além disso, a confiança é um importante preditor de apoio político, um elemento central do processo político, pois como argumenta Arthur Miller, "um sistema político democrático não pode sobreviver por muito tempo sem o apoio da maioria de seus cidadãos" (MILLER, 1974). Uma vez que é muito improvável que o apoio possa estar presente onde a confiança esteja ausente, esta tem a mesma importância que o apoio para a sobrevivência do regime democrático.

Há indícios suficientes para mostrar que a confiança é um preditor robusto de apoio ao sistema e que quanto mais baixo o nível de confiança nas instituições políticas, menor a tendência a apoiar o sistema político. Uma insatisfação duradoura com o governo pode ter conseqüências importantes, como sugere Miller: "[...] é muito provável que os sentimentos de impotência e falta de normas sejam acompanhados de hostilidade contra os líderes políticos e sociais, as instituições de governo e o regime como um todo" (MILLER, 1974).

Provas da existência dessa mesma relação no contexto latino-americano, bem como no contexto político boliviano, são apresentados na série de relatórios que o programa LAPOP da Vanderbilt University vem produzindo periodicamente desde 1998 (SELIGSON, 1998, 1999a, 2003; SELIGSON et al., 2004a; SELIGSON et al., 2005). Os dados mostram também que os níveis de confiança institucional na Bolívia são muito baixos quando comparados com os de outros países da América Latina. ${ }^{5}$ (ver Anexo)

Tendo em vista a importância da confiança política na dinâmica política, a principal motivação deste artigo é explorar quais os fatores que influenciam a confiança institucional na Bolívia e quais a influenciam de tal modo que podem ser considerados preditores da confiança institucional. Essa motivação parece especialmente importante no contexto político boliviano, devido ao esforço supostamente bem sucedido que o Estado boliviano fez para aperfeiçoar sua estrutura institucional e os baixos níveis de confiança e a instabilidade política que o país ainda enfrenta.

\footnotetext{
${ }^{5}$ Ver estudos do LAPOP para países centro-americanos, Bolívia e Equador em www.lapopsurveys.org. Ver também "Bolivia: Democracy Audit" de 1998, 2000, 2002 e 2004 publicados pelo LAPOP com Both, Pittsburgh University (1998 a 2002) e Vanderbilt University (2004), USAID Bolivia e Encuestras y Estudios.
} 
De acordo com a definição de confiança política utilizada neste trabalho, nos concentraremos somente na confiança que os bolivianos registram em relação a suas instituições políticas e não estudaremos a confiança em políticos, políticas públicas, campanhas ou no governo em andamento. Quanto aos preditores de confiança institucional, este trabalho explorará os fatores que o púbico considera quando avalia o desempenho das instituições em relação a suas expectativas.

Os indícios sugerem que a confiança política e seus preditores podem variar entre grupos sociais dentro da mesma comunidade política; podem variar também com as características demográficas da população e com as instituições. Ou seja, a confiança política não é homogênea, mas distribuída de modo desigual para as diferentes instituições ou cenários institucionais, para diferentes conjuntos de políticas, pode ser considerada de modo diferente entre homens e mulheres, jovens e velhos, pode variar conforme grupos de renda e pessoas com diferentes níveis de instrução, de acordo com o local onde as pessoas moram e sua afiliação étnica (CITRIN, 1974; MILLER, 1974; SELIGSON, 1980; ABRAMSON e FINIFER, 1981; SELIGSON, 1998, 1999a; CITRIN, 2002; MOORE, 2002; SELIGSON et al., 2004b; HETHERINGTON, 2005; SELIGSON et al., 2005).

Este trabalho explorará a possibilidade de encontrar preditores comuns para diferentes instituições baseado na consideração de que a confiança institucional é definida pela satisfação com a estrutura do processo político e que essa estrutura tem de ser comum para todas as instituições no sistema político, portanto, deve haver preditores que são comuns a todas as instituições.

Os dados do LAPOP medem a confiança institucional em uma escala de 0 a 100 e oferecem provas da variação em níveis de confiança em várias instituições ao longo do tempo na Bolívia. Em geral, os níveis de confiança institucional são baixos e somente pouquíssimas instituições apresentam escores acima do ponto médio da escala, embora novos dados apresentem indícios de um possível aumento dos níveis em 2006. O Gráfico seguinte mostra a variação da confiança institucional na Bolívia para 2006. Escores próximos de zero indicam níveis baixos de confiança e próximos de cem indicam altos níveis de confiança nas instituições. 
Gráfico 1

Confiança institucional na Bolívia, 2006

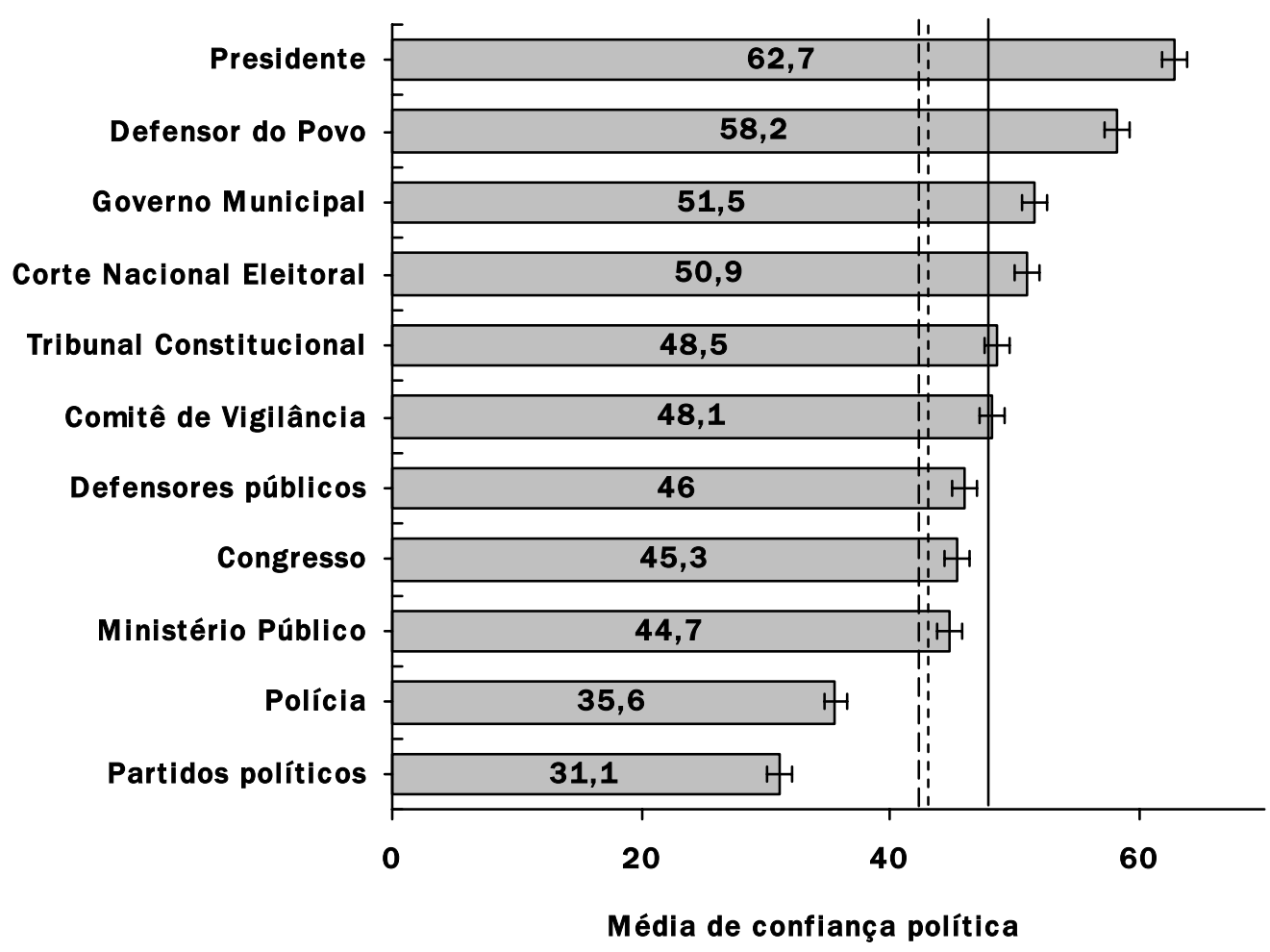

Casos ponderados por variável de ponderação - pondera departamentos por tamanho da população Barras de erro: $95 \%$ IC

Diante dos dados exibidos no Gráfico 1, fica claro que os níveis de confiança nas instituições políticas são baixos na Bolívia, mas também que há diferenças consideráveis de confiança entre as instituições. No Gráfico, a linha cheia mostra a média de confiança nas instituições em 2006, enquanto que a linha grossa pontilhada mostra essa média em 2004. O nível médio de confiança nessas instituições em 2006 é de 47,9 pontos na escala de 100. A diferença entre as 
médias de 2006 e 2004 é de seis pontos na escala de 0.100 e as diferenças de médias são significativas no nível de 0,05 para todas as instituições, exceto para o Defensor do Povo, que mantém um nível relativamente alto de confiança.

A linha pontilhada mais fina representa o nível médio de confiança nas mesmas instituições em 2002, cinco pontos mais baixa que em 2006. As diferenças de médias entre 2002 e 2006 são significantes no nível de 0,05 para todas as instituições, exceto para os defensores públicos. Instituições como os partidos políticos e o Congresso mostram uma melhoria significativa em confiança desde 2004, assim como o presidente e a polícia. ${ }^{6}$

Embora um aumento da confiança política não fosse predito entre $2004 \mathrm{e}$ 2006, é razoável dizer que poderia ser esperado, tendo em vista os acontecimentos no campo político dos últimos dois anos que levaram à eleição de Evo Morales, o primeiro presidente boliviano de ascendência indígena da história do país. Morales ganhou a eleição presidencial de 2005 com 53\% dos votos e sua ascensão simboliza para os bolivianos não somente uma mudança na estrutura do poder, mas uma mudança significativa na concepção do Estado boliviano e na visão de mundo que deve ser adotada como diretriz para a reforma do Estado.

Este trabalho testa duas hipóteses:

1. que as percepções do público sobre a situação econômica nacional, sobre corrupção na administração pública e sobre o desempenho do governo são os principais preditores da confiança institucional no contexto político boliviano;

2. que há preditores de confiança institucional comuns para todas as instituições políticas independentemente de sua função no governo.

Para fazer isso, trabalhamos com dados de quatro amostras nacionais conduzidas entre 2000 e 2006 e estudamos onze instituições para as quais existem dados em todas as amostras. Os testes incluem um estudo de efeitos fixos do tempo e efeitos fixos das diferentes sub-unidades nacionais em que as amostras nacionais são estratificadas.

\footnotetext{
${ }^{6}$ A amostra de 2006 foi feita na Bolívia dois meses depois da posse do novo presidente Evo Morales, em 22 de janeiro. Portanto, seus dados podem estar influenciados pelo assim chamado período de "lua-de. mel" do novo governo, o que afeta possivelmente as apreciações subjetivas e percepções como a da confiança política.
} 


\section{As amostras}

As amostras estão disponíveis para 2000, 2002, 2004 e 2006, e os dados foram coletados em todo o território nacional por meio de entrevistas pessoais com indivíduos de mais de 18 anos de idade. Todas são amostras probabilísticas nacionais representativas da população nacional no nível de estados (sub-unidades nacionais). Em todas as residências selecionadas para a amostra somente uma pessoa foi entrevistada e foram realizadas no total das pesquisas 12.016 entrevistas. A idade média dos respondentes é de 37 anos.

Quando se trabalha com questões atitudinais como a confiança política, não se deve esquecer que se lida com percepções e respostas movidas por afetos. Os padrões atitudinais podem ser encontrados e podem ser analisados estatisticamente de forma confiável, mas não são necessariamente definitivos nem são estáveis no longo prazo, ou em todos os grupos sociais ou comunidades políticas. Apesar dessas dificuldades, amplos indícios empíricos dão suporte à robustez e exatidão dos resultados de estudos de confiança política sob as condições descritas. No contexto latino-americano, as pesquisas e os relatórios do LAPOP são uma ampla prova disso (SELIGSON, 1980, 1989, 1998, 1999a, 1999b, 2003; SELIGSON et al., 2004a, 2004b, 2005).

Embora o LAPOP venha estudando as percepções e comportamentos democráticos do público boliviano desde 1998, este trabalho usa apenas os dados coletados a partir de 2000 pois apenas as amostras de 2000-2006 contêm uma lista extensa de instituições.

\section{O modelo}

A questão que mede o nível de confiança revelado pelos respondentes em cada uma das onze instituições incluídas neste estudo tem a mesma estrutura para todas as instituições e diz o seguinte: Até que ponto tem confiança em...? A variável é originalmente medida numa escala de 7 pontos em que 1 significa que o respondente não confia nada na instituição e 7 significa que confia muito. As variáveis foram depois transformadas numa escala de 0.100 para facilitar a interpretação dos resultados.

A Tabela 1 mostra as questões das pesquisas do LAPOP Bolívia 2000-2006 para os propósitos da pesquisa deste trabalho. As questões da Tabela 1 são apenas uma parte da série do LAPOP sobre confiança institucional, originalmente formulada em espanhol. 
Tabela 1

Questões das pesquisas LAPOP Bolívia sobre confiança nas instituições (2004)

\begin{tabular}{|l|}
\hline Questões da pesquisa LAPOP Bolívia 2004 \\
\hline B21. Até que ponto você confia nos partidos políticos? \\
\hline B11. Até que ponto você confia na Corte Nacional Eleitoral? \\
\hline B13. Até que ponto você confia no Congresso? \\
\hline B18. Até que ponto você confia na polícia? \\
\hline B21A. Até que ponto você confia no presidente? \\
\hline B32. Até que ponto você confia no governo municipal? \\
\hline BOLB22C. Até que ponto você confia no comitê de vigilância municipal? \\
\hline BOLB23A. Até que ponto você confia no Ministério Público? \\
\hline B17. Até que ponto você confia no Defensor do Povo? \\
\hline BOLB23E. Até que ponto você confia no Tribunal Constitucional? \\
\hline B44. Até que ponto você confia nos Defensores Públicos? \\
\hline
\end{tabular}

O modelo pressupõe que os respondentes não conhecem necessariamente todas as instituições sobre as quais são perguntados ou a função que desempenham no governo. Portanto, eles não consideram necessariamente as instituições em si mesmas, como unidades isoladas, ao determinar seu nível de confiança nelas, mas as avaliam em relação com a área em que atuam e em relação com as outras instituições que pertencem à mesma área, sobre as quais têm pelo menos uma idéia.

Digamos que um respondente não tem uma noção clara sobre o que é ou faz o Ministério Público. Mas ele terá pelo menos uma idéia do que o ramo judiciário do governo faz e será capaz de relacionar o MP com o judiciário e usar sua percepção dele para formar uma opinião a respeito. ${ }^{7}$

Esse pressuposto baseia-se também no fato de que nem todos os respondentes têm conhecimento específico sobre todas as instituições no momento da entrevista e, portanto, podem responder às questões e determinar o nível de confiança nelas baseados na relação que há entre as instituições que não conhecem e aquelas que conhecem na mesma área. ${ }^{8}$

\footnotetext{
7 Embora não seja um processo ideal, é um procedimento provável do respondente quando confrontado com questões desconhecidas em uma pesquisa de opinião pública.

8 Não é possível distinguir especificamente quais respondentes conhecem realmente as instituições sobre as quais são perguntados e quais os que não as conhecem, uma vez que eles não se mostram muito dispostos a admitir que não têm pistas sobre questões que parecem relevantes. Nossos pressupostos são reforçados pelo fato de que os respondentes tentarão dar a resposta mais sincera possível e relacionar questões desconhecidas com as conhecidas a fim de oferecer uma resposta.
} 
O modelo de regressão linear multivariada estima a confiança institucional em relação ao efeito das variáveis sociotrópicas, desemprego, percepções da extensão da corrupção na administração pública e desempenho do governo na luta contra a pobreza, e contra a corrupção e na promoção dos princípios democráticos na Bolívia. ${ }^{9}$

Outras variáveis medem o desempenho do presidente correspondente a cada ano, a participação em protestos públicos e em organizações políticas de nível local e nacional como uma medida da intensidade do capital social dos respondentes (PUTNAM, 2001).

O modelo inclui também uma medida de sofisticação política e três variáveis que medem a exposição a mensagens da mídia através de televisão, rádio e jornais. ${ }^{10}$ Essas variáveis medem se os respondentes conhecem questões básicas da política nacional e internacional e se eles obtêm informações sobre política de diferentes meios de comunicação. As variáveis que medem a confiança interpessoal, a tolerância política e a concordância com formas de participação política agressiva, como manifestações públicas e ocupação de espaços públicos entre outras, estão incluídas junto com variáveis sócio-demográficas, usadas como variáveis de controle.

As expectativas quanto aos resultados do modelo são que os valores negativos das variáveis sociotrópicas (a percepção atual e futura da economia nacional) produzirão uma diminuição da confiança institucional. Do mesmo modo, espera-se que à medida que aumenta a percepção da disseminação da corrupção no governo, o público ficará menos inclinado a confiar nas instituições.

É lógico esperar que uma melhora na avaliação do desempenho do presidente aumente a disposição do público de confiar nas instituições. Quanto aos efeitos da sofisticação política e da exposição à mídia, espera-se que a primeira aumente a confiança nas instituições, ao passo que é difícil predizer o efeito da exposição à mídia sem medir a intensidade da exposição e sem levar em conta os conteúdos das mensagens dos meios de comunicação. ${ }^{11}$ A Tabela 2 apresenta as variáveis que fazem parte do modelo.

\footnotetext{
${ }^{9}$ A pesquisa foi realizada em abril de 2004, quando o presidente Carlos D. Mesa ainda estava no cargo.

10 As perguntas específicas usadas para medir essas questões estão no anexo, junto com o resto das perguntas utilizadas para este trabalho.

11 O efeito da exposição à mídia sobre os respondentes será diferente conforme a intensidade da exposição - ou seja, quantas vezes por semana o respondente assiste ao noticiário na tevê, lê o jornal e/ou escuta as notícias no rádio - e do conteúdo da mensagem, e se o respondente compara ou não as notícias das diferentes fontes. Este trabalho não analisa a exposição à mídia em todos os detalhes, mas pergunta apenas de qual tipo de meio de comunicação os respondentes obtêm suas informações.
} 
Tabela 2

Variáveis independentes no modelo

\begin{tabular}{|l|l|}
\hline Variáveis explicativas & Variáveis de controle \\
\hline Percepção da corrupção & Sexo \\
Percepção da situação econômica atual & Idade \\
Percepção da situação econômica futura & Grau de instrução \\
Desemprego (dicotômica) & Nível de renda \\
Sofisticação política & Riqueza (medida em propriedade de bens \\
Exposição a notícias na televisão & materiais) \\
Exposição a notícias no rádio & Urbano (cidades com mais de 2000 habitantes) \\
Exposição a notícias nos jornais & Sul (variável regional) \\
Percepção do desempenho do presidente & Oriente (variável regional) \\
Participação política agressiva & El Alto (variável regional) \\
Tolerância política & Mestiço (dummy de etnicidade) \\
Confiança interpessoal & Indígena (dummy de etnicidade) \\
\hline
\end{tabular}

Em trabalho anterior, esse modelo foi analisado em relação às variáveis institucionais arranjadas em quatro grupos de acordo com sua função e área de desempenho (SCHWARZ-BLUM, 2006). Na ocasião, o modelo testou hipóteses similares às testadas aqui, com uma diferente disposição das variáveis dependentes institucionais. Este trabalho testa as mesmas hipóteses sobre confiança nas institucionais políticas, mas aperfeiçoa a estimação dos preditores ao revisar a conceituação das variáveis dependentes e, em vez de agrupá-las de acordo com um critério teórico, o faz conforme o que os respondentes pensam delas, usando uma análise fatorial das variáveis institucionais.

Medindo a confiança política

A confiança política é tratada aqui como uma variável dependente e é medida por meio de onze variáveis individuais que representam a estrutura institucional do Estado boliviano. Uma vez que a confiança é concebida como o grau de satisfação com o modo como o processo político boliviano é estruturado, é necessário levar em conta todas as onze variáveis dependentes que compõem a estrutura institucional do Estado. Surge então um problema do fato de que há onze variáveis individuais que representam as variáveis dependentes neste estudo. 
A maneira de resolver esse problema foi agrupar as variáveis dependentes de acordo com os componentes principais subjacentes resultantes de análise fatorial exploratória realizada sobre eles. (ver Anexo)

A análise fatorial identificou três fatores que estruturam a escala de confiança nas instituições que utilizamos. A matriz dos componentes rotados indica que as variáveis com cargas maiores no fator 1 são polícia, Congresso, partidos políticos, Ministério Público, Defensores Públicos e Tribunal Constitucional.

As instituições com cargas mais altas no fator 2 são o presidente, o governo municipal, o comitê de vigilância, o Defensor do Povo, os defensores públicos e o Tribunal Constitucional. As instituições com cargas mais altas no fator 3 são o presidente e o Tribunal Nacional Eleitoral.

Qual é o elemento comum entre as instituições que define mais 'carga' em algum fator? Qual o conceito subjacente que os une para os respondentes bolivianos?

À primeira vista, podemos notar o posicionamento conflitante do presidente, do Tribunal Constitucional e dos defensores públicos. No caso do Tribunal, o conflito se deve provavelmente à pura confusão, devido à sua novidade e ao fato de que os respondentes não têm muita certeza quanto às funções que ele desempenha exatamente, e não sabem bem com que instituições ele está relacionado. A mesma confusão pode explicar o caso dos defensores públicos, além do fato de que os respondentes podem relacioná-los com o Ombudsman (na Bolívia denominado Defensor do Povo e é uma instituição muito popular). Desse modo, os níveis de confiança atribuídos ao Defensor do Povo podem estar sendo transferidos para os defensores públicos nos casos em que a função desses não está muito clara para os respondentes. As incertezas em relação a essas instituições, levam a que sejam consideradas parte de ambos os grupos e a análise separada dos grupos torna mais claro o que os respondentes pensam a respeito delas.

O caso do presidente é diferente, pois suas cargas são distribuídas quase igualmente nos fatores 2 e 3 . Que fator comum têm as três instituições no fator 3 , eis uma questão intrigante. Uma hipótese aceitável diria que a autoridade é o conceito subjacente que molda o fator 3: o presidente encarna a autoridade do Estado, e o Tribunal Nacional Eleitoral, embora não relacionado ao uso da força, pode ser visto como uma autoridade governante, dada sua transformação na última década. ${ }^{12} \mathrm{O}$ Tribunal administra o registro dos cidadãos em todos os processos eleitorais e ganhou respeito ao organizar e efetuar eleições limpas e transparentes, não

\footnotetext{
12 A Corte Nacional Eleitoral ganhou não apenas visibilidade na última década, mas também o respeito do público em geral devido à promoção de uma imagem mais limpa - limpa de corrupção - e de eficiência melhorada devido a um esforço óbvio de modernização das instituições, não somente do ponto de vista tecnológico, mas também conceitual. A Corte cuidou bem de "tornar-se pública" e deixar as pessoas saberem em que ela trabalha e como está fazendo seu trabalho.
} 
contestadas e reconhecidas internacionalmente como tal. Em geral, suas decisões não são contestadas pelo público e um sentimento geral de simpatia e respeito parecia ser o "clima" da população em relação ao Tribunal até a eleição presidencial de $2005 .^{13}$

Ao observar o grupo de instituições que são determinadas principalmente pelo fator 2, vemos que todas as instituições políticas que funcionam nos níveis local e regional formam o cerne desse grupo. Observamos também uma carga relativamente alta do presidente nesse fator. O Defensor do Povo conta fortemente com esse fator e os casos dos defensores públicos e do Tribunal Constitucional já foram explicados.

Nossa hipótese é que é a idéia de proximidade que conduz esse fator. As instituições locais e regionais estão mais próximas dos cidadãos do que o governo nacional. São instituições que o povo pode conhecer e ter fácil acesso. O caso do Defensor do Povo encaixa-se perfeitamente nisso, pois é uma instituição muito popular que ganhou o respeito dos cidadãos ao tornar-se acessível e trabalhar perto do povo. ${ }^{14}$

Essas instituições não são idéias abstratas do Estado, mas a única presença real dele para muitos grupos de cidadãos. Se é a proximidade que conduz o pensamento dos respondentes nesse fator, devemos presumir que até agora descobrimos que os respondentes bolivianos pensam o quão as instituições estão próximas deles, ou quão acessível e o quanto são uma figura de autoridade ou não.

O último fator é o fator 1 , cujo cerne de instituições é composto por várias instituições ligadas ao poder judiciário e ao processo da justiça. O Congresso, os partidos políticos e a polícia também apresentam carga significativa. A primeira coisa que nos ocorre quando buscamos um conceito comum a essas instituições é a corrupção. Todas elas são consideradas muito corruptas, enfrentaram escândalos de corrupção e tendem a ter baixa confiança dos cidadãos. Na verdade, os dados do LAPOP indicam que os partidos políticos têm o escore mais baixo em confiança de todas as instituições, seguidos de perto pelo Congresso e a polícia, seguidos pelas instituições do poder judiciário.

A análise fatorial propiciou uma nova visão de como os respondentes pensam sobre as instituições políticas e os níveis de confiança que inspiram nos cidadãos. Esse instrumento também tem o valor adicional de resolver um problema

\footnotetext{
13 Nas eleições presidenciais de 2005, quase 750 mil cidadãos bolivianos foram impedidos de votar. As regras da Corte para compor a lista de cidadãos aptos a votar foram questionadas pelo presidente eleito Evo Morales e por muitas fontes públicas, e foram chamadas até de "fraudulentas". É provável que não tenham seguido os melhores critérios, mas o público esqueceu que elas foram aprovadas pelo Congresso nos meses anteriores às eleições e que a Corte tinha pouco a fazer senão aplicá-las.

14 Além disso, o Defensor do Povo tem escritórios regionais em cada um dos nove departamentos do país e trabalha com profissionais locais.
} 
recorrente na análise de opinião pública: a noção de que os respondentes têm uma opinião e respondem às perguntas sem ter um conhecimento profundo da questão. Em nosso caso, ela nos mostrou que os respondentes podem construir uma opinião e confiar ou desconfiar das instituições que mal conhecem recorrendo ao "sentimento" subjacente sobre essas instituições e relacionando-as com questões como corrupção, proximidade ou senso de autoridade - e com outras instituições que conhecem melhor - como uma opinião geral sobre as instituições do poder judiciário -, a função geral que as instituições desempenham ou os espaços públicos em que realizam suas funções.

A utilidade desse instrumento aplicado às pesquisas de opinião justifica-se pelo fato de que não aspiramos colher dados somente de cidadãos muito informados e politicamente sofisticados, pois o processo político não funciona exclusivamente através das ações e percepções desses cidadãos. Em vez disso, aspiramos obter uma melhor compreensão de como o cidadão comum, menos informado ou aquele que se engaja apenas esporadicamente, obtém informações sobre o processo político, forma opiniões e convicções e age de acordo com elas.

Uma vez que os índices construídos com base na análise fatorial serão as variáveis dependentes neste estudo, aplicou-se um teste de confiabilidade. Os resultados desse teste mostram que o índice de corrupção tem o nível mais alto de confiabilidade, com um coeficiente de 0,889, e o índice de proximidade segue muito próximo, com um coeficiente de 0,849. O índice de autoridade tem um coeficiente menor de 0,634. Os altos coeficientes indicam que os índices são confiáveis. A seção $\mathrm{E}$ do Anexo deste trabalho contém Tabelas complementares que mostram que nenhuma escala pôde ser melhorada com a eliminação de algum de seus elementos e que ambas as escalas já estão em seu nível melhor de confiabilidade.

\section{Os resultados}

O modelo para a base de dados coletados entre 2000-2006 tenta não somente testar as hipóteses postuladas no início deste trabalho, mas também captar elementos específicos que podem afetar os dados e que não são captados pelas variáveis incluídas inicialmente no modelo estimativo.

Quando se analisa dados coletados ao longo do tempo, um dos elementos com alta chance de ser negligenciado é exatamente o efeito da passagem do tempo entre as amostras, com efeito direto ou indireto, quando há fenômenos que ocorrem no tempo, mas que não são captados pelas variáveis no modelo. $O$ espaço é outro elemento importante. A região ou um local específico fundamental dentro de um país também pode ter uma influência significativa na moldagem da visão de mundo 
individual e, portanto, no comportamento e na percepção do Estado e do mundo ao seu redor. A relativa importância desse fator dependerá da força da dinâmica regional do país e das características dos outros elementos que participam da cena política.

Tendo em vista a dinâmica política entre regiões que vem se desenvolvendo na Bolívia nos últimos seis anos, e levando em conta que no estudo feito em trabalhos anteriores foi encontrada uma significação regional importante na determinação dos níveis de confiança política, a segunda parte deste trabalho estima o modelo que controla os efeitos fixos das nove sub-unidades nacionais em que a amostra nacional boliviana foi estratificada.

Esse modelo também estima os efeitos fixos da passagem do tempo entre as amostras nacionais em vez dos efeitos aleatórios, o que é apropriado pois o tempo decorrido entre as amostras ocasionou fenômenos importantes na cena política boliviana, seguramente exercendo ao menos alguma influência no modo como os respondentes consideram o Estado e o processo político. Entre as amostras de 2000 e 2002, o governo de centro-direita de um ex-ditador eleito presidente chegou ao fim mergulhado na recessão econômica e na ineficácia governamental. Entre 2002 e 2004, a Bolívia elegeu um novo presidente de centrodireita com uma clara tendência econômica neoliberal, que foi o primeiro presidente a não completar seu mandato desde o retorno à democracia, em 1982. Entre 2004 e 2006, a cena política boliviana mudou rapidamente e o primeiro presidente de ascendência indígena foi eleito em 2005.

A Tabela 3 mostra o modelo estimado para as amostras de 2000-2006 que inclui uma estimativa dos efeitos fixos nas sub-unidades nacionais ao longo do tempo. La Paz é tomada como a variável de região de referência e variáveis dummy para as outras oito regiões estão incluídos no modelo de regressão. 
SCHWARS-BLUM, V. Por quê confiamos nas instituições?

Tabela 3

Resultados de regressão com efeitos fixos por sub-unidade nacional, 2000-2006 ${ }^{15}$

\begin{tabular}{|c|c|c|c|c|c|c|}
\hline \multirow{2}{*}{ Variáveis } & \multicolumn{2}{|c|}{ Índice de corrupção } & \multicolumn{2}{|c|}{ Índice de proximidade } & \multicolumn{2}{|c|}{ Índice de autoridade } \\
\hline & B & $T$ & B & $T$ & B & $\mathbf{T}$ \\
\hline Dummy para sexo (fem.) & 0,268 & 0,321 & 0,234 & 0,275 & $-1,262$ & $-1,273$ \\
\hline Grupos de renda & $1,287 *$ & 1,822 & $2,936 * * *$ & 4,09 & $3,131 * * *$ & 3,741 \\
\hline Idade & $-0,377$ & $-1,428$ & 0,004 & 0,016 & $0,649 * *$ & 2,073 \\
\hline Instrução & 0,352 & 0,514 & 0,891 & 1,281 & 0,634 & 0,782 \\
\hline Riqueza & $-0,308$ & $-1,503$ & $-1,01 * * *$ & $-4,855$ & $-0,566 * *$ & $-2,334$ \\
\hline Urbano & $-2,234 * \star$ & $-2,107$ & 0,621 & 0,577 & $-1,108$ & $-0,882$ \\
\hline El Alto & $-5,219 *$ & $-1,656$ & 0,486 & 0,152 & 1,321 & 0,354 \\
\hline Mestiço & 0,725 & 0,754 & 0,949 & 0,971 & 0,005 & 0,005 \\
\hline Indígena & $-1,15$ & $-0,820$ & $-0,471$ & $-0,33$ & $-0,584$ & $-0,352$ \\
\hline Notícias no rádio & $-0,001$ & $-0,003$ & $-0,081$ & $-0,248$ & 0,119 & 0,313 \\
\hline Notícias na TV & $-0,524$ & $-1,314$ & $-0,653$ & $-1,613$ & $-0,769$ & $-1,629$ \\
\hline Jornais & $-0,352$ & $-1,063$ & $-0,665 * *$ & $-1,978$ & $-0,161$ & $-0,411$ \\
\hline Conhecimento político & $-0,572$ & $-1,426$ & $-0,375$ & $-0,921$ & 0,079 & 0,167 \\
\hline Corrupção disseminada & $-0,057 * \star *$ & $-4,011$ & $-0,035 * *$ & $-2,404$ & $-0,018$ & $-1,080$ \\
\hline Economia atual & $0,097 * * *$ & 4,559 & $0,094 * * *$ & 4,344 & $0,109 * * *$ & 4,352 \\
\hline Economia futura & $0,063 * * *$ & 5,933 & $0,076 * * *$ & 7,079 & $0,096 * * *$ & 7,704 \\
\hline Desemprego & 0,850 & 0,872 & 1,573 & 1,578 & 1,841 & 1,593 \\
\hline Desempenho presidencial & $0,085 * * *$ & 3,954 & $0,175 * * *$ & 7,994 & $0,330 * * *$ & 12,936 \\
\hline Confiança interpessoal & $0,046 * * *$ & 3,415 & $0,061 * * *$ & 4,460 & $0,047 * *$ & 2,934 \\
\hline Participação política agressiva & $0,147 * * *$ & 5,924 & $0,069 * *$ & 2,731 & 0,021 & 0,715 \\
\hline Índice de tolerância política & $0,089 * * *$ & 4,879 & $0,107 * * *$ & 5,744 & $0,082 * * *$ & 3,771 \\
\hline Santa Cruz & $7,021 * * *$ & 4,365 & $2,709 *$ & 1,657 & $5,291 * * *$ & 2,776 \\
\hline Cochabamba & 1,493 & 0,946 & 2,323 & 1,448 & $3,808 * *$ & 2,035 \\
\hline Oruro & 0,137 & 0,081 & $-0,390$ & $-0,228$ & 3,335 & 1,670 \\
\hline Chuquisaca & $3,633 * * *$ & 2,11 & 2,556 & 1,461 & 3,444 & 1,689 \\
\hline Potosí & 0,074 & 0,043 & 0,606 & 0,346 & $-0,479$ & $-0,235$ \\
\hline Pando & 10,077 *** & 5,621 & 4,854 ** & 2,664 & $7,342 * * *$ & 3,455 \\
\hline Tarija & $5,307 * *$ & 3,105 & 4,689 ** & 2,699 & 4,604 ** & 2,273 \\
\hline Beni & 10,678 *** & 6,16 & $6,999 * * *$ & 3,973 & $8,518 * * *$ & 4,146 \\
\hline $\mathbf{N}$ & 1985 & & 1985 & & 1985 & \\
\hline$R^{2}$ ajustado & 0,177 & & 0,178 & & 0,213 & \\
\hline $\mathrm{F}$ & 0,000 & & 0,000 & & 0,000 & \\
\hline
\end{tabular}

*** significante no nível de 0,01 ** significante no nível de 0,05* significante no nível de 0,1

\footnotetext{
${ }^{15}$ A estimação para este modelo foi feita sem aplicar ponderações pós-design. As amostras das unidades sub-nacionais foram colhidas com casos suficientes para serem representativas por si mesmas.
} 
Os resultados na Tabela 3 oferecem indícios para sustentar a primeira hipótese deste trabalho. Com efeito, a consideração da situação econômica nacional, seja atual ou futura, é um preditor significante dos níveis de confiança política, indicando que quando as percepções da economia melhoram, o mesmo acontece com a disposição de confiar nas instituições políticas. A significação da variável renda reforça a importância das considerações econômicas na avaliação da estrutura política em todos os grupos de diferentes instituições, mostrando que à medida que a renda aumenta, as pessoas tendem a confiar mais nas instituições.

As percepções do desempenho presidencial e da disseminação da corrupção entre as autoridades públicas também influenciam os níveis de confiança, embora a da corrupção não o faça para todos os grupos de instituições. O impacto da tolerância à participação política do "oposto" é importante porque ela influencia um aumento da confiança nas instituições independentemente do grupo a que pertençam. Embora esses resultados sejam uma boa notícia, pois oferecem indícios que confirmam a hipótese 1 , os efeitos substanciais dessas variáveis são pequenos se comparados com os de outras variáveis do modelo. Todas as variáveis dependentes ou independentes - foram registradas em escalas de 0-100 ou 0-1, o que torna seus coeficientes $B$ relativamente comparáveis.

Levando-se isso em conta, segue-se que as variáveis que exercem mais influência na confiança política nas amostras bolivianas são as regionais, aquelas que pertencem à mesma região mais ampla, com os mesmos interesses econômicos e objetivos de desenvolvimento, baseados no acesso a recursos naturais e de hidrocarbonetos, e não algumas variáveis regionais aleatórias. Os resultados mostram que as pessoas que vivem nessa região ampliada que abrange o leste e parte do sul do país confiam mais na estrutura institucional do Estado do que aquelas que moram em La Paz.

Esses resultados fornecem mais indícios que corroboram as conclusões do estudo de 2004, ou seja, que a dinâmica política regional desempenha um papel importante na moldagem das atitudes e percepções dos bolivianos em relação ao Estado e que há uma diferença significativa entre as percepções das pessoas que vivem no leste e no oeste do país. Parece que no caso da Bolívia, a importância da dinâmica regional supera a influência de preditores tradicionais de confiança, como a sofisticação política e a exposição à mídia, que não apresentam nenhum impacto neste modelo.

Em geral, o modelo oferece indícios para confirmar a hipótese 2, pela qual, dado que a estrutura institucional do Estado é apenas uma, deve haver preditores de confiança que sejam comuns para todos os tipos de instituições e que possam predizer de modo significante a confiança em todos os grupos de instituições. Os resultados apresentados na Tabela 3 nos ajudam a confirmar isso. 
SCHWARS-BLUM, V. Por quê confiamos nas instituições?

Para aprofundar a análise, a Tabela 4 apresenta o resultado dos efeitos fixos estimados dos anos 2002, 2004 e 2006, tomando o ano de 2000 como categoria de referência.

Tabela 4

Resultados da regressão com efeitos fixos de tempo, 2000-2006

\begin{tabular}{|c|c|c|c|c|c|c|}
\hline \multirow{2}{*}{ Variáveis } & \multicolumn{2}{|c|}{ Índice de corrupção } & \multicolumn{2}{|c|}{ Índice de proximidade } & \multicolumn{2}{|c|}{ Índice de autoridade } \\
\hline & B & $T$ & B & $\mathbf{T}$ & B & $T$ \\
\hline Dummy para sexo (fem.) & 0,16 & 0,343 & $-0,385$ & $-0,809$ & $-1,882 * * *$ & $-3,408$ \\
\hline Grupos de renda & $0,757 * *$ & 2,054 & $1,472 * * *$ & 3,914 & $2,021 * * *$ & 4,634 \\
\hline Idade & $-0,441 * * *$ & $-3,334$ & $-0,2$ & $-1,481$ & $0,370 * *$ & 2,366 \\
\hline Instrução & $-0,335$ & $-0,907$ & $-0,365$ & $-0,968$ & 0,336 & 0,769 \\
\hline Urbano & $-3,082 * * *$ & $-5,374$ & $-1,698 * *$ & $-2,899$ & $2,266 * * *$ & $-3,338$ \\
\hline Sul & $1,816 * *$ & 2,937 & $1,413 * *$ & 2,239 & 0,308 & 0,42 \\
\hline Oriente & $7,312 * * *$ & 12,976 & $3,244 * * *$ & 5,64 & $4,107 * * *$ & 6,158 \\
\hline El Alto & $-5,458 * * *$ & $-4,31$ & $-1,296$ & $-1,003$ & $-2,561 *$ & $-1,708$ \\
\hline Mestiço & 0,829 & 1,489 & 0,458 & 0,806 & $-1,071$ & $-1,625$ \\
\hline Indígena & $-0,989$ & $-1,218$ & $-1,083$ & $-1,305$ & $-2781 * *$ & $-2,892$ \\
\hline Notícias no rádio & $-0,048$ & $-0,261$ & $-0,338^{*}$ & $-1,811$ & $-0,036$ & $-0,165$ \\
\hline Notícias na TV & $-0,303$ & $-1,283$ & $-0,058$ & $-0,241$ & $-0,345$ & $-1,231$ \\
\hline Jornais & $-0,11$ & $-0,6$ & $-0,127$ & $-0,684$ & 0,057 & 0,266 \\
\hline Corrupção disseminada & $-0,068 * * *$ & $-8,122$ & $-0,047 * * *$ & $-5,463$ & $-0,031 * *$ & $-3,134$ \\
\hline Economia atual & $0,078 * * *$ & 6,4 & $0,060 * * *$ & 4,847 & $0,063 * * *$ & 4,375 \\
\hline Economia futura & $0,055 * * *$ & 8,706 & $0,070 * * *$ & 10,81 & $0,082 * * *$ & 10,892 \\
\hline Desemprego & 0,549 & 0,983 & $1,427 * *$ & 2,506 & $1,658 * *$ & 2,511 \\
\hline Desempenho presidencial & $0,095 * * *$ & 7,503 & $0,191 * * *$ & 14,709 & $0,290 * * *$ & 19,294 \\
\hline Confiança interpessoal & $0,039 * * *$ & 4,962 & $0,049 * * *$ & 6,1 & $0,044 * * *$ & 4,801 \\
\hline $\begin{array}{l}\text { Participação política } \\
\text { agressiva }\end{array}$ & $0,129 * * *$ & 9,043 & $0,076 * * *$ & 5,245 & $0,029 *$ & 1,71 \\
\hline Índice de tolerância política & $0,097 * * *$ & 9,266 & $0,104 * * *$ & 9,694 & $0,072 * * *$ & 5,839 \\
\hline 2002 & $-0,442$ & $-0,639$ & $-0,276$ & $-0,39$ & $5,283 * * *$ & 6,453 \\
\hline 2004 & $-1,459$ ** & $-2,103$ & 1,415 ** & 1,998 & 7,665 *** & 9,332 \\
\hline 2006 & $1,27^{*}$ & 1,676 & $3,451 * * *$ & 4,458 & $9,843 * * *$ & 10,969 \\
\hline $\mathbf{N}$ & 5914 & & 5914 & & 5914 & \\
\hline $\mathrm{R}^{2}$ ajustado & 0,162 & & 0,169 & & 0,224 & \\
\hline$F$ & 0 & & 0 & & 0 & \\
\hline
\end{tabular}


Abordando a análise da perspectiva do tempo, encontramos alguns elementos interessantes e também desse ponto de vista, nossas hipóteses obtêm mais provas que as sustentam. As percepções da situação econômica nacional no presente e no futuro são preditores significativos de confiança nas instituições, assim como as do desempenho do presidente e da disseminação da corrupção em todos os grupos de instituições e ao longo do tempo, pois as variáveis são significantes nos dados reunidos de 2000-2006. Quanto mais as pessoas pensam que a economia vai bem, quanto mais acham que o presidente está se saindo bem e menos percebem corrupção nos negócios públicos, mais confiança demonstram nas instituições. Aqui também a renda é um preditor significativo de confiança e quanto mais renda ganham, mas confiam nas instituições.

As variáveis regionais do modelo confirmam a análise dos efeitos fixos por região e o estudo anterior para 2004: uma diferença significativa entre as regiões leste (Oriente) e oeste do país no modo como as instituições são percebidas e, portanto, a atitude em relação à estrutura institucional do Estado boliviano.

Os efeitos dos anos 2004 e 2006 são significativos em todos os grupos de instituições, tal como esperado, mas em ambos os casos, eles parecem influenciar um aumento dos níveis de confiança política. Era o que se esperava da amostra de 2006, devido ao efeito "lua-de-mel" com o novo governo de Evo Morales, mas não da amostra de 2004. O efeito de 2004 é negativo somente para as variáveis do índice de corrupção, sendo positivo para o resto das instituições.

Algumas variáveis novas interessantes mostram que a tolerância quanto à participação política daqueles que discordam do sistema atual aumenta a disposição para confiar nas instituições, bem como o sentimento de que se vive num bairro confiável.

Quando não se controla especificamente os efeitos geográficos, o grau de urbanização influencia os níveis de confiança nas instituições: as pessoas que vivem em cidades maiores do que dois mil habitantes confiam menos do que as que vivem em cidades menores e áreas rurais. Este é um dado interessante quando se leva em conta que, há dez anos, a população boliviana estava distribuída de forma quase igual entre o campo e a cidade e que hoje, essa distribuição mudou um pouco, com o aumento da população urbana, enquanto a rural está um pouco abaixo de $40 \%$.

$\mathrm{Na}$ estimação dos efeitos fixos da confiança política também encontramos novos indícios que confirmam as hipóteses postuladas no início deste trabalho, ou seja, que os preditores de confiança são estáveis ao longo do tempo e para todas as instituições, e que as considerações econômicas, bem como as percepções de corrupção e desempenho presidencial são preditores robustos da confiança na esfera política boliviana. 


\section{Considerações finais}

Os resultados do estudo apresentados neste artigo oferecem provas empíricas de que a confiança institucional é, de fato, um processo de avaliação e uma atitude, em vez de apenas uma percepção afetiva do estado do campo político. Ela é influenciada por outras variáveis e não varia aleatoriamente entre os indivíduos.

Em geral, e contra o que se poderia esperar, descobrimos que região geográfica, os respondentes residentes em áreas urbanas, as percepções de corrupção na administração pública, a avaliação do desempenho do governo em questões fundamentais, os níveis de conhecimento político, a discordância de um golpe de estado são todos preditores confiáveis da confiança institucional e são comuns a todas as instituições, independentemente do seu campo de atuação e de sua relação com outras instituições.

Os resultados apontam para dois processos diferentes que se unem na esfera política boliviana: um que se desenvolve ao longo do tempo e que não tem nenhum padrão estável de evolução (a confiança aparentemente aumenta e diminui em resposta a debates ou situações políticas relevantes); e outro que se desenvolve no contexto espacial, que parece estar relacionado com a dinâmica política regional, que pode estar conectada com o modo como a população boliviana em diferentes regiões geopolíticas vive sua relação com o Estado, e que também pode estar ligado a um padrão de distribuição de recursos e benefícios.

O processo parece ser mais "limpo" quando abordado do ponto de vista regional e tende a ser mais complexo quando analisado ao longo do tempo, o que se poderia esperar. Além da dinâmica regional, outros fatores entram em jogo no espaço público e influenciam as avaliações que os bolivianos fazem da estrutura do Estado.

Os resultados também parecem oferecer provas que corroboram apenas parcialmente a primeira hipótese proposta neste trabalho, pois embora as variáveis sociotrópicas e a percepção da corrupção sejam significantes no modelo, há outras variáveis que parecem ter influência mais substancial que essas e que as variáveis de avaliação do desempenho presidencial. Ao contrário do esperado, o preditor mais forte da confiança institucional em termos de efeitos substanciais parece ser a região geográfica em que o respondente reside, com efeitos polarizados entre residentes do leste e do oeste do país.

Quando controlamos os efeitos fixos das regiões, a aparente tensão entre duas delas que surgiu na análise de 2004 desaparece no contexto mais amplo e dá lugar a uma explicação mais complexa e mais abrangente da dinâmica política regional. Os padrões de confiança nas sub-unidades nacionais caem em regiões geográficas com interesses econômicos compartilhados e proporcionam uma 
melhor compreensão de como o lugar em que a pessoa vive pode ser determinante para suas opiniões sobre o Estado. O controle dos efeitos fixos por sub-unidades nacionais oferece definitivamente um conhecimento útil da dinâmica política nacional.

Apesar dos profundos problemas econômicos e do alto grau de corrupção na Bolívia, os preditores de confiança institucional não estão ligados exclusivamente às percepções de corrupção ou da situação econômica nacional, mas parecem antes fortemente fundados em algumas características demográficas da população boliviana. À primeira vista, esses fatores demoGráficos podem parecer estar desligados de considerações econômicas e podem sugerir que a urgência de uma situação socioeconômica crítica pode não prevalecer sobre outros fatores mais duradouros na determinação da confiança institucional. Ao pensarmos um pouco mais, fica claro que as diferenças regionais na Bolívia não estão totalmente desligadas das condições econômicas, tais como a distribuição de renda ${ }^{16}$ e o bem. estar geral.

Verificamos que a situação econômica pessoal dos respondentes pode estar se sobrepondo às variáveis regionais, no sentido de que quanto mais elevado o nível de renda, mais os respondentes confiam nas instituições. Isso é interessante porque podemos pensar que as instituições com um alto grau percebido de corrupção são mais acessíveis às pessoas com mais recursos econômicos, mas isso não deveria necessariamente significar que as pessoas mais ricas confiam mais nessas instituições.

Uma outra consideração pode ser valiosa no que tange à influência de variáveis sociotrópicas na confiança institucional. O modelo de análise não consegue discriminar entre uma situação econômica percebida como ruim e uma situação econômica realmente difícil na Bolívia. Isso significa que as pessoas podem ter uma percepção de situação econômica ruim mesmo quando isso não é necessariamente verdade. A presença de uma diferença entre uma situação percebida e a situação real em um longo período de tempo é tão perturbadora quanto o fato da pobreza afetar os níveis de confiança difusa no país mais pobre da América do Sul. É preciso encontrar uma explicação para essa diferença, mas é essa questão para outro estudo.

Sabemos também que altos níveis de renda estão tradicionalmente ligados a altos graus de educação e pessoas mais instruídas podem ter um conhecimento melhor de como as instituições políticas funcionam. De novo, em um contexto em que se pensa que as instituições são corruptas, ineficientes e fracas, não se espera

\footnotetext{
16 Os dados do LAPOP para 2004 registram diferenças estatisticamente significativas em níveis de renda informados entre os respondentes que vivem na região leste do país e os que moram em cidades como El Alto, nos departamentos da região oeste (como Oruro e Potosí).
} 
que as pessoas mais instruídas confiem mais do que as menos instruídas, mas os respondentes com níveis mais altos de conhecimento político confiam mais nas instituições políticas independentemente de suas funções. Contudo, o nível médio de conhecimento político na amostra boliviana é de apenas 2,1 em uma escala de 0 a 6 e, portanto, não se poderia esperar altos níveis de confiança baseados apenas no efeito dessa variável.

Se esse argumento está correto, teríamos de pensar em duas clivagens sobrepostas que afetam a confiança institucional: uma econômica e uma regional que encontra expressão na afiliação ou afirmação étnica e numa polarização de interesses expressa geograficamente na tensão entre a população do leste e a do oeste do país.

Do ponto de vista metodológico, isso significa que os efeitos regionais da confiança institucional não são necessariamente preditores mais robustos do que as considerações econômicas, mas que devem ser analisados em conjunto, como termos interativos, a fim de conseguir avaliar os verdadeiros efeitos de ambos os elementos sobre a confiança institucional. Se essas considerações fossem apoiadas por mais indícios, a hipótese da influência das percepções econômicas sobre a confiança institucional seria mais reforçada pelas evidências do que este trabalho indica.

Essa nova abordagem também esclareceria o efeito significativo da variável étnica dicotômica que representa a população que se define como mestiça e seu efeito contrário, pois ela mostra uma relação positiva com as instituições contida no grupo do índice de corrupção. Isso significa que os respondentes que se consideram mestiços tendem a confiar nessas instituições mais do que os que não se consideram mestiços. Por outro lado, os respondentes mestiços tendem a confiar menos nas instituições contidas nos grupos do índice de autoridade do que os não-mestiços. O quê essa relação indica? Os respondentes mestiços perdoam mais a corrupção ou confiam menos na autoridade? Há outros fatores intervenientes que mediam a relação entre a identificação étnica como mestiço e a confiança institucional?

As considerações da corrupção na administração pública importam, mas com menos intensidade do que o esperado e proposto na primeira hipótese. Parece que os bolivianos perdoam as práticas corruptas, seja porque as vêem já institucionalizadas na administração pública, ou porque a corrupção pode ser conveniente desde que torne as instituições mais acessíveis aos indivíduos, ou ainda porque não Ihes causa mal, a não ser que tenham uma experiência pessoal negativa com ela.

O quê esses resultados nos dizem sobre a situação atual na Bolívia? Temos uma tensão de interesses entre regiões geográficas específicas que afeta profundamente o modo como os cidadãos avaliam e confiam nas instituições 
políticas. Vemos aqui que a dinâmica política regional têm uma influência mensurável específica sobre o processo político em nível nacional.

Temos um problema econômico que está corroendo a confiança dos cidadãos em suas instituições, apesar dos esforços do governo para combater a pobreza, e mesmo apesar da avaliação bastante positiva do desempenho do governo nessa questão específica, a consideração de uma situação econômica inquietante está causando uma erosão da confiança no regime democrático. Tendo em vista que se trata do país mais pobre da América do Sul e levando-se em conta esses resultados, não deve surpreender que a Bolívia é também o país com os níveis mais baixos de apoio ao sistema e de confiança nas instituições entre outros países da América Latina. ${ }^{17}$

Temos também um problema de corrupção que causa desconfiança nas instituições políticas e uma população com grau baixo de conhecimento sobre as questões políticas básicas que poderia utilizar mais conhecimento para avaliar melhor o desempenho das instituições.

Apesar dos esforços do Estado boliviano para reformar e aperfeiçoar suas instituições, há muitos elementos no contexto político e econômico que vão de encontro a esses esforços e influenciam uma falta geral de confiança do público boliviano nas instituições políticas. Trata-se de um problema grave que precisa ser enfrentado com seriedade pelo governo, pois corrupção e economia pobre não são condições que se mudam ou apagam no curto prazo e elas continuarão a afetar a confiança que os bolivianos têm em suas instituições.

Além das descobertas valiosas derivadas da análise da confiança institucional, os resultados apresentados neste trabalho abrem novas linhas para pesquisas futuras e para uma compreensão mais profunda da dinâmica da confiança institucional em um contexto político conturbado como o da Bolívia.

\footnotetext{
17 Os países para os quais o LAPOP possui dados são: Costa Rica, Guatemala, Honduras, Nicarágua, El Salvador, República Dominicana, Panamá, México, Colômbia, Equador e Bolívia. Dentre todos eles, mesmo os mais pobres da América Central, a Bolívia tem os níveis mais baixos de apoio ao sistema na região.
} 


\section{Referências Bibliográficas}

ABRAMSON, P. R.; FINIFTER, A. W. On the meaning of political trust: new evidence from items introduced in 1978. American Journal of Political Science, v. 25, n. 2, p. 297-307, 1981.

CITRIN, J. Democracy and trust. Political Psychology, v. 23, n. 2, p. 402-04, 2002.

CITRIN, J. Comment: the political relevance of trust in government. The American Political Science Review, v. 68, n. 3, p. 973-88, 1974.

EASTON, D. A systems analysis of political life. Nova York: Wiley, 1965.

A re-assessment of the concept of political support. British Journal of Political Science, v. 5, p. $435-57,1975$.

GARSON, D. Factor analysis general concepts. North Carolina State University.

HETHERINGTON, M. J. Why trust matters. Declining political trust and the demise of american liberalism. Princeton: Princeton University Press, 2005.

LIPSET, S. M. Political man: the social basis of politics. Ed. Ampl. Baltimore: Johns Hopkins University Press, 1981.

MILLER, A. H. Political issues and trust in government: 1964-1970. The American Political Science Review, v. 68, n. 3, p. 951-72, 1974.

MISHLER, W.; ROSE, R. Trust, distrust and skepticism: popular evaluations of civil and political institutions in post-communist societies. The Journal of Politics, v. 59, n. 2, p. 418-51, 1997.

MOORE, D. W. Just one question: the myth and mythology of trust in government. Public Perspective, 2002.

SCHWARZ-BLUM, V. Confianza en las instituciones: por que es necesaria?. ed. Daniel Moreno. Cochabamba: USAID Bolivia, 2006.

SELIGSON, M. A. Trust, efficacy and modes of political participation: a study of Costa Rican peasants." British Journal of Political Science, v. 10, p. 75-98, 1980. 
. On the measurement of diffuse support: some evidence from Mexico. Social Indicators Research, v. 12, p. 1-24, 1983.

Latin american legislatures: an overview of Bolivia, Chile and Peru. Pittsburgh:

University of Pittsburgh Latin American Democratization Study Group, 1989.

. The political culture of democracy in Bolivia: 1998. La Paz, Bolivia: USAID/LAPOP 1998.

. La cultura política de la democracia boliviana. La Paz: Encuestas \& Estudios, 1999a.

. Popular support for regional economic integration in Latin America. Journal of Latin

American Studies, v. 31, part 1, p. 129-50, 1999b.

Auditoria de la Democracia: Bolivia 2002. La Paz: USAID, 2003.

SELIGSON, M. A.; AMES, B.; PEREZ-LIÑAN, A.; MORENO-MORALES, D. Elites, Instituciones y el público: una nueva mirada a la democracia boliviana. La Paz: Pittsburg University/USAID, 2004a.

SELIGSON, M. A.; MORENO-MORALES, D.; CATSAM, M.; LOTZ, A. Auditoria de la Democracia Ecuador 2004. Quito: Vanderbilt University/CEDATOS, 2004b.

SELIGSON, M. A.; MORENO-MORALES, D.; SCHWARZ-BLUM, V. Auditoria de la democracia: informe Bolivia 2004. La Paz: USAID/ Vanderbilt University, 2005a.

TUCKER, L. R.; MACCALLUM, R. Exploratory Factor Analysis. 1997. Disponível em: <http://www.unc.edu/ rcm/book/factornew.htm>.

WEATHERFORD, M. S. Measuring political legitimacy. American Political Science Review, v. 86, n. 1, p. 149.66, 1992. 


\section{ANEXOS}

Tabela A

Matriz de correlações para todas as variáveis incluídas no modelo

\begin{tabular}{|l|c|c|c|c|c|c|c|c|c|c|c|c|c|c|c|}
\hline & b21a & b12 & B18 & b44 & b11 & b13 & b30 & b33 & b22 & B22c & b31a & b23a & b23c & b23nr & b23b \\
\hline b12 FFAA & 0,28 & 1 & 0,38 & 0,24 & 0,47 & 0,47 & 0,30 & 0,35 & 0,29 & 0,27 & 0,39 & 0,31 & 0,22 & 0,36 & 0,24 \\
\hline b18 polícia & 0,26 & 0,38 & 1 & 0,27 & 0,30 & 0,46 & 0,35 & 0,39 & 0,33 & 0,33 & 0,39 & 0,42 & 0,26 & 0,43 & 0,36 \\
\hline b44 DPA & 0,38 & 0,24 & 0,27 & 1 & 0,33 & 0,32 & 0,26 & 0,33 & 0,29 & 0,32 & 0,30 & 0,40 & 0,35 & 0,39 & 0,38 \\
\hline b11 CNE & 0,34 & 0,47 & 0,30 & 0,33 & 1 & 0,43 & 0,38 & 0,35 & 0,31 & 0,28 & 0,48 & 0,37 & 0,27 & 0,37 & 0,34 \\
\hline b13 Congresso & 0,25 & 0,47 & 0,46 & 0,32 & 0,43 & 1 & 0,45 & 0,46 & 0,35 & 0,45 & 0,50 & 0,49 & 0,29 & 0,48 & 0,39 \\
\hline $\begin{array}{l}\text { b30 partidos } \\
\text { políticos }\end{array}$ & 0,20 & 0,30 & 0,35 & 0,26 & 0,38 & 0,45 & 1 & 0,36 & 0,33 & 0,32 & 0,41 & 0,40 & 0,17 & 0,38 & 0,32 \\
\hline b33 Prefeitura & 0,39 & 0,35 & 0,39 & 0,33 & 0,35 & 0,46 & 0,36 & 1 & 0,58 & 0,48 & 0,40 & 0,49 & 0,39 & 0,43 & 0,41 \\
\hline b22 Gov. Municipal & 0,47 & 0,29 & 0,33 & 0,29 & 0,31 & 0,35 & 0,33 & 0,58 & 1 & 0,47 & 0,33 & 0,40 & 0,32 & 0,34 & 0,34 \\
\hline $\begin{array}{l}\text { b22c Comitê } \\
\text { Vigilância }\end{array}$ & 0,26 & 0,27 & 0,33 & 0,32 & 0,28 & 0,45 & 0,32 & 0,48 & 0,47 & 1 & 0,35 & 0,52 & 0,43 & 0,41 & 0,37 \\
\hline b31a Corte Suprema & 0,28 & 0,39 & 0,39 & 0,30 & 0,48 & 0,50 & 0,41 & 0,40 & 0,33 & 0,35 & 1 & 0,51 & 0,27 & 0,56 & 0,42 \\
\hline $\begin{array}{l}\text { b23a Ministério } \\
\text { Público }\end{array}$ & 0,29 & 0,31 & 0,42 & 0,40 & 0,37 & 0,49 & 0,40 & 0,49 & 0,40 & 0,52 & 0,51 & 1 & 0,45 & 0,60 & 0,47 \\
\hline $\begin{array}{l}\text { b23c Defensor do } \\
\text { Povo }\end{array}$ & 0,26 & 0,22 & 0,26 & 0,35 & 0,27 & 0,29 & 0,17 & 0,39 & 0,32 & 0,43 & 0,27 & 0,45 & 1 & 0,36 & 0,40 \\
\hline b23nr Trib. Justiça & 0,29 & 0,36 & 0,43 & 0,39 & 0,37 & 0,48 & 0,38 & 0,43 & 0,34 & 0,41 & 0,56 & 0,60 & 0,36 & 1 & 0,57 \\
\hline b23b Def.Públicos & 0,30 & 0,24 & 0,36 & 0,38 & 0,34 & 0,39 & 0,32 & 0,41 & 0,34 & 0,37 & 0,42 & 0,47 & 0,40 & 0,57 & 1 \\
\hline
\end{tabular}

** as correlações são significantes no nível de 0,001 (teste bilateral)

Como se pode ver na Tabela $A$, os coeficientes de correlação entre as variáveis que compõem nossas quatro variáveis dependentes estão geralmente em torno de 0,3 (com poucas exceções), o que é suficientemente indicativo da independência das variáveis uma das outras e significa que estamos trabalhando com variáveis que são diferentes umas das outras. 
Gráfico B

Apoio ao sistema na Bolívia comparado com outros países latino-americanos em 2004

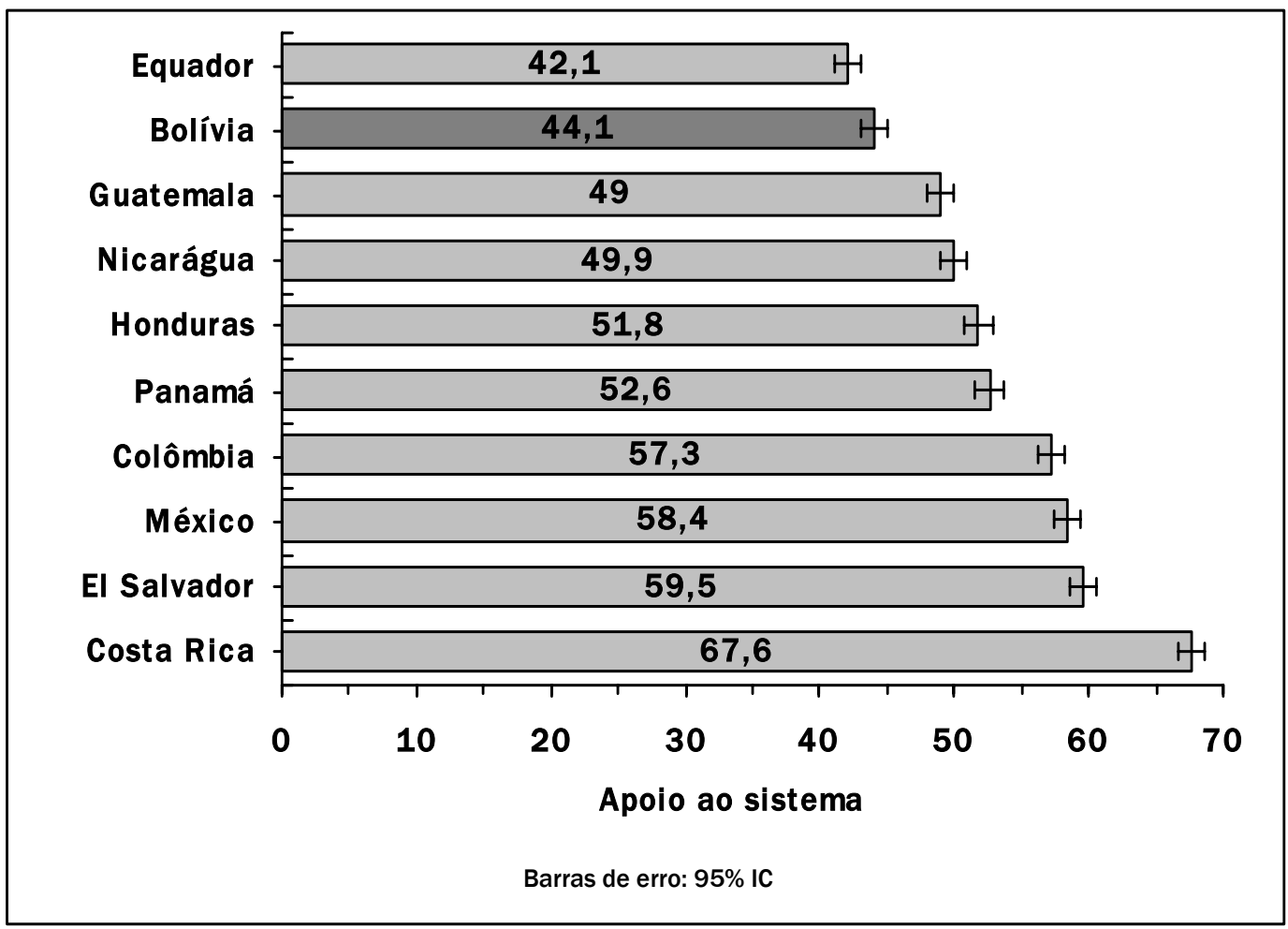


Tabela C

Barômetro Global da Corrupção - 2004

Em que medida você percebe que os seguintes setores

deste país estão afetados pela corrupção? (1: não corrupto; 5 : muito corrupto)

\begin{tabular}{|c|c|c|c|c|c|c|c|c|c|c|c|c|c|c|c|}
\hline & 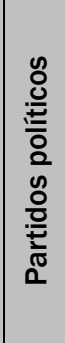 & 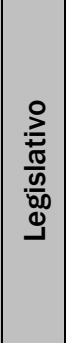 & 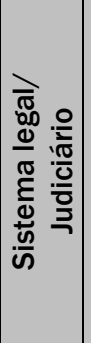 & $\frac{. \frac{\pi}{0}}{\frac{20}{0}}$ & 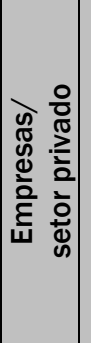 & $\begin{array}{l}\text { o } \\
\text { ஸे } \\
\text { 을 } \\
\underline{\underline{E}}\end{array}$ & $\begin{array}{l}\frac{\pi}{00} \\
\frac{0}{00} \\
\frac{0}{0} \\
\frac{\pi}{\pi} \\
\frac{\pi}{4}\end{array}$ & $\stackrel{\frac{\pi}{0}}{\frac{\pi}{2}}$ & 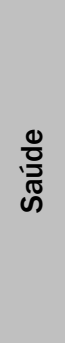 & 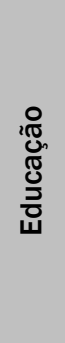 & 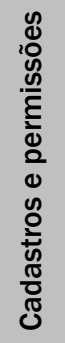 & 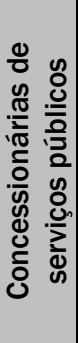 & 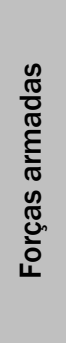 & ¿্ & 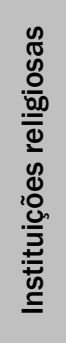 \\
\hline Argentina & 4,6 & 4,6 & 4,3 & 4,4 & 3,7 & 3,6 & 4,2 & 3,5 & 3,3 & 3,1 & 3,8 & 3,7 & 3,4 & 2,9 & 3,0 \\
\hline Bolívia & 4,5 & 4,3 & 4,0 & 4,2 & 3,2 & 3,6 & 4,2 & 2,8 & 3,0 & 3,0 & 3,0 & 3,0 & 3,6 & 2,7 & 2,2 \\
\hline Brasil & 4,5 & 4,3 & 4,2 & 4,4 & 3,8 & 4,2 & 3,9 & 3,6 & 3,9 & 3,9 & 3,6 & 3,8 & 3,4 & 3,0 & 3,0 \\
\hline Costa Rica & 4,5 & 4,3 & 4,0 & 4,2 & 3,8 & 4,3 & 4,1 & 3,6 & 4,4 & 3,8 & 3,5 & 4,1 & 0,0 & 3,6 & 4,2 \\
\hline Equador & 4,9 & 4,8 & 4,5 & 4,3 & 3,2 & 3,5 & 4,4 & 3,0 & 3,3 & 3,5 & 4,3 & 3,7 & 3,6 & 3,1 & 2,8 \\
\hline Guatemala & 4,2 & 4,1 & 4,1 & 4,2 & 3,9 & 4,1 & 4,1 & 3,7 & 3,8 & 3,8 & 3,7 & 3,9 & 3,8 & 3,6 & 3,2 \\
\hline México & 4,5 & 4,2 & 4,3 & 4,5 & 3,7 & 4,0 & 4,0 & 3,6 & 3,5 & 3,4 & 3,8 & 3,7 & 3,2 & 3,3 & 3,1 \\
\hline Peru & 4,6 & 4,5 & 4,5 & 4,5 & 3,9 & 4,1 & 3,8 & 4,2 & 3,9 & 4,0 & 4,2 & 3,9 & 4,2 & 3,9 & 2,8 \\
\hline Uruguai & 4,3 & 4,1 & 3,9 & 4,2 & 3,6 & 3,3 & 4,2 & 3,4 & 3,3 & 3,1 & 3,0 & 3,1 & 3,5 & 2,6 & 3,1 \\
\hline USA & 3,6 & 3,3 & 3,3 & 2,9 & 3,0 & 3,2 & 2,6 & 3,5 & 3,0 & 2,8 & 2,2 & 2,9 & 2,5 & 2,6 & 2,5 \\
\hline Venezuela & 4,1 & 4,2 & 4,3 & 4,2 & 3,8 & 3,9 & 3,9 & 4,0 & 4,0 & 3,9 & 3,8 & 3,6 & 3,6 & 3,5 & 3,3 \\
\hline Amostra Total & 4,0 & 3,7 & \begin{tabular}{|l|}
3,6 \\
\end{tabular} & 3,6 & 3,4 & 3,4 & 3,3 & 3,3 & 3,3 & 3,1 & 3,0 & 3,0 & 2,9 & 2,8 & 2,7 \\
\hline
\end{tabular}

Fonte: Transparency International Global Corruption Barometer 2004

Os setores estão listados da esquerda para a direita segundo seus escores globais. As células sombreadas indicam a/o instituição/setor mais bem avaliado em cada país.

D. Análise fatorial e alguns resultados

A análise fatorial revela a linha subjacente de pensamento dos respondentes e nos permite ver os objetos de análise da perspectiva deles. Nossa tarefa é então descobrir quais são esses pensamentos subjacentes e o que impulsiona os respondentes quando eles pensam sobre as instituições políticas em seus países.

A análise fatorial é um estudo matemático da ordem e da estrutura dos dados multivariados. Ela é usada no campo da psicologia para analisar a estrutura subjacente do pensamento dos pacientes (TUCKER e MacCALLUM, 1997). 
No caso específico deste trabalho, a análise fatorial contribui para analisar o pensamento subjacente dos respondentes de pesquisas de opinião pública que responderam aos questionários do LAPOP na Bolívia. Isso é possível porque ela analisa a estrutura latente ou as dimensões que compõem os dados. Ela tenta explicar a variabilidade em variáveis aleatórias observadas por meio do encontro de elementos ou fatores aleatórios menores, mas inobserváveis, que compõem os dados. Em outras palavras, a análise fatorial "[...] reduz o espaço atribuído a um grande número de variáveis a um número menor de fatores e, desse modo, é um procedimento 'não-dependente' (ou seja, não assume uma variável dependente especificada)" (GARSON).

Para fazer isso, as variáveis analisadas por meio desse instrumento são decompostas em seus fatores componentes e analisadas numa matriz de dados com tantas dimensões quantos forem os fatores componentes dos dados. Essa matriz é rotada a fim de identificar as relações entre dimensões de diferentes variáveis e, como resultado, a análise mostra a carga* de cada variável inicial em cada uma dos fatores componentes. Quanto mais alta a carga de uma variável num fator, mais variabilidade da variável aquele fator explica.

A carga das variáveis em cada componente aparece representada por um coeficiente que varia entre 0 e 1 , em que os números mais próximos de 1 indicam uma forte carga no componente e números próximos de 0 apontam para uma carga fraca no componente.

Há duas principais linhas de aplicação da análise fatorial: a exploratória e a explanatória. Este trabalho utiliza a análise fatorial exploratória para descobrir a idéias subjacentes dos respondentes bolivianos quando perguntados sobre seu grau de confiança em várias instituições políticas diferentes que desempenham funções governamentais. A principal expectativa da análise fatorial realizada sobre as variáveis institucionais era propor um arranjo das instituições completamente diferente daquele feito de acordo com critérios teóricos, pois é provável que os respondentes pensem nas instituições baseados em sua experiência mais do que em critérios teóricos abstratos.

\footnotetext{
* Uma carga é o coeficiente de correlação entre a variável e seu fator.
} 


\section{Rotated Component Matrix ${ }^{\mathrm{a}}$}

\begin{tabular}{|l|c|c|c|}
\hline \multirow{2}{*}{} & \multicolumn{3}{|c|}{ Fatores } \\
\cline { 2 - 4 } & $\mathbf{1}$ & $\mathbf{2}$ & $\mathbf{3}$ \\
\hline b21ar Presidente & $-0,012$ & 0,594 & 0,538 \\
\hline b12 Forças Armadas & 0,296 & 0,106 & 0,760 \\
\hline b18r Polícia & 0,570 & 0,227 & 0,307 \\
\hline b44r Delegaça anti-corrupção & 0,238 & 0,504 & 0,273 \\
\hline b11r Tribunal Nacional Eleitoral & 0,305 & 0,222 & 0,701 \\
\hline b13r Congresso & 0,622 & 0,302 & 0,318 \\
\hline b30r Partidos Políticos & 0,652 & 0,117 & 0,183 \\
\hline b33r Prefeitura & 0,372 & 0,595 & 0,278 \\
\hline b22r Governo Municipal & 0,246 & 0,655 & 0,262 \\
\hline b22cr Comitê de Vigilância & 0,392 & 0,601 & $-0,002$ \\
\hline b23cr Defensor do Povo & 0,083 & 0,726 & 0,116 \\
\hline bn23xyz Tribunais de Justiça & 0,696 & 0,454 & 0,088 \\
\hline b10ar & 0,788 & 0,135 & 0,185 \\
\hline b31ar Supremo Tribunal de Justiça & 0,743 & 0,197 & 0,280 \\
\hline b23ar Fiscais & 0,615 & 0,553 & 0,051 \\
\hline b23br Defensores Públicos & 0,512 & 0,561 & 0,041 \\
\hline b23er Tribunal Constitucional & 0,562 & 0,506 & 0,193 \\
\hline
\end{tabular}

Extraction Method: Principal Component Analysis.

Rotation Method: Varimax with Kaiser Normalization.

a Rotation converged in 8 iterations.

\section{E. Testes de confiabilidade}

O teste de confiabilidade* analisa a coerência interna de uma escala com elementos múltiplos, e o grau de confiabilidade (expresso pelo valor do alfa de Cronbach) é indicado por um coeficiente que varia de 0 a 1 , em que 1 indica correlação perfeita entre os elementos e 0 informa que os elementos da escala não se combinam, pois podem estar medindo coisas completamente diferentes.

\footnotetext{
* O teste fornece também uma lista de elementos na escala e um coeficiente de confiabilidade potencial no caso em que o elemento tenha sido eliminado da escala. Essa informação adicional nos possibilita saber se a escala poderia ser melhorada com a eliminação de um elemento que não se correlaciona muito bem com o resto dos elementos dela.
} 


\section{Tabelas E1, E2 e E3}

Análise de confiabilidade para índices de corrupção, proximidade e autoridade

\section{Estatística de confiabilidade}

\begin{tabular}{|c|c|}
\hline Alfa de Cronbach & $n^{\circ}$. de itens \\
\hline 0,889 & 9 \\
\hline
\end{tabular}

Tabela E1

\section{Estatística de confiabilidade}

\begin{tabular}{|c|c|}
\hline Alfa de Cronbach & $n^{\circ}$. de itens \\
\hline 0,849 & 8 \\
\hline
\end{tabular}

Tabela E2

Estatística de confiabilidade

\begin{tabular}{|c|c|}
\hline Alfa de Cronbach & $n^{\circ}$. de itens \\
\hline 0,634 & 3 \\
\hline
\end{tabular}

Tabela E3

Tabelas E1, E2 and E3. Análise de confiabilidade para indicadores de corrupção, proximidade e autoridade.

Esta é uma versão atualizada de dois artigos anteriores, um apresentado no Congresso da LASA en San Juan, Porto Rico, em março de 2006, o outro publicado na Bolívia como capítulo do livro La cultura política de los bolivianos: aproximaciones cuantitativas, eds. Mitchell A. Seligson e Daniel Moreno. Vanderbilt University, LAPOP/USAID/Cidadanía. Cochabamba, 2006.

Recebido para publicação em agosto de 2006. Aprovado para publicação em agosto de 2006.

Tradução de Pedro Maia Soares. 